\title{
Hjernens hemodynamiske respons ved stillingsendring hos friske nyfødte målt med NeoDoppler
}

Anders H. Jarmund ${ }^{\text {, }}$

Siv S. Ødegård ${ }^{1,2}$,

Hans Torp ${ }^{1}$,

Siri Ann Nyrnes ${ }^{1,2}$

Institutt for sirkulasjon og bildediagnostikk, NTNU ${ }^{1}$ og Barne- og ungdomsklinikken, St. Olavs Hospital², Trondheim, Norge

Norge har en lang tradisjon i utvikling av Doppler-ultralyd, med Angelsens PEDOF og Kristoffersen og Grips ALFRED som viktige innovasjoner. Dette la grunnlaget for en blomstrende norsk ultralydindustri som i dag dekker en stor del av verdensmarkedet innen kardiovaskulær ultralyd [1]. Et nytt tilskudd til rekken av Doppler-teknologi fra ultralydgruppa ved NTNU er NeoDoppler, utviklet med professor Hans Torp i spissen. NeoDoppler-systemet består av en liten og lett probe ( $8 \mathrm{MHz})$, samt ultralydskanner med tilhørende programvare og visningsenhet [2]. NeoDoppler måler blodstrømshastigheter (blood flow velocity, BFV) i flere dybder samtidig ned til $35 \mathrm{~mm}$, og kan benyttes til kontinuerlig Dopplerovervåkning av hjernens BFV via den fremre fontanellen hos nyfødte.
Vi har nylig benyttet NeoDoppler til å studere hva som skjer med nyfødtes hjernesirkulasjon når de løftes opp fra liggende stilling [3]. Førtifire nyfødte ble løftet fra ryggleie og vippet 90 grader inn mot brystet, mens barnet hadde NeoDoppler-proben festet over fontanellen ( $\triangleright$ Fig. 1). Dette ble gjort første og andre dag etter fødsel, og NeoDoppler-overvåkningen foregikk sammenhengende i fem minutter. NeoDoppler-systemet beregner automatisk en kvalitetsscore for opptaket, og tilstrekkelig kvalitet ble oppnådd hos over $80 \%$ av barna. Typiske årsaker til forringet kvalitet
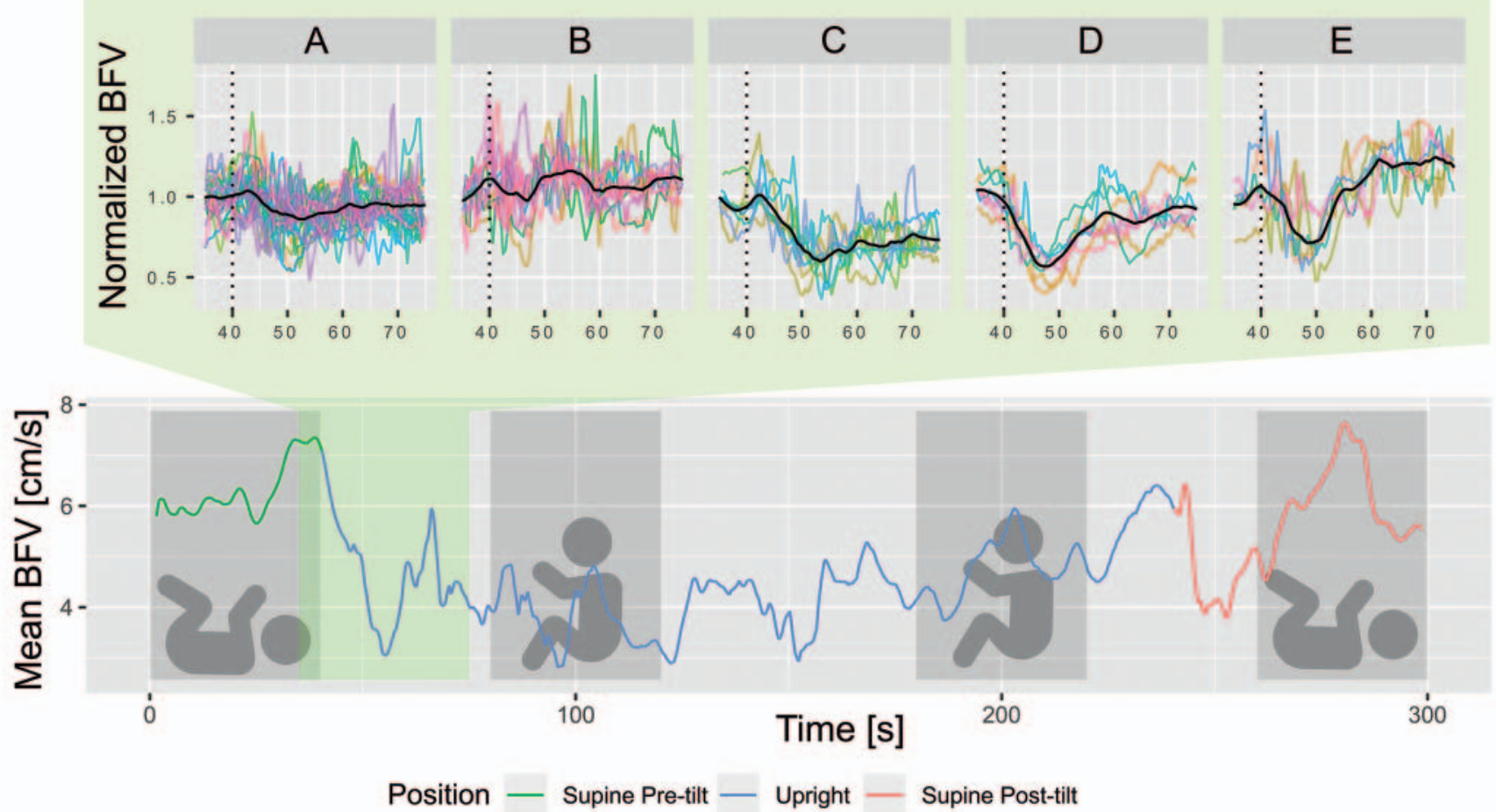

- Fig. 1 Kurven viser gjennomsnittlig blodstrømshastighet per hjerteslag gjennom det fem minutter lange forsøket. Barnet ble løftet opp og holdt i vertikal posisjon i perioden 40-240 s (blå linje). De grå rutene viser de fire tidsvinduene brukt for videre analyse, med barnets stilling indikert nederst. I tillegg ble den øyeblikkelige vippe-responsen studert i perioden merket grønt. Vi fant fem distinkte responser A-E, som vist i den grønne boksen øverst i figuren. 
var at barnet ble urolig, lagde lyder eller at proben flyttet seg litt under vippingen. Gjennomsnittlig BFV (mean BFV, mBFV) ble hentet ut og brukt i videre analyse. $\mathrm{Vi}$ hentet også ut gjennomsnittlig pulsatilitetsindeks (PI), hjerterate (HR) og mBFV i fire tidsvinduer på 40 sekunder ( Fig. 1). I tillegg brukte vi et vindu på 40 sekunder fra mBFV-kurven til å se den øyeblikkelige forandringen i mBFV ved løftingen.

Ikke-veiledet cluster-analyse [4] avdekket fem karakteristiske, øyeblikkelige responser i mBFV (A-E øverst i > Fig. 1). Vi fant at de ulike øyeblikkelige responsene var assosierte med noe ulike forløp i PI, HR og mBFV regnet som gjennomsnitt over 40 sekunder (Mørke ruter i - Fig. 1). Samme barn kunne presentere ulik respons på første og andre dag etter fødsel. Blodtrykk målt før forsøket og endring i blodtrykk etter å ha blitt løftet opp var ikke relatert til respons. Disse funnene er forenlige med hva som er beskrevet tidligere [5, 6], men med flere målte parametere og tidsforløp over en lengre periode. Den kliniske betydningen av disse normalresponsene må utforskes i større studier.
Vi mener at Doppler-teknologien fortsatt har potensiale til å bidra med ny kunnskap i klinikken. NeoDoppler kan måle blodstrømshastighet over tid, og er et nytt eksempel på Doppler-teknologi med en lang rekke anvendelsesområder. I denne studien har vi vist at NeoDoppler er i stand til å detektere raske endringer i BFV, HR og PI. Vi ser fram til å benytte NeoDoppler til å studere ulike kliniske tilstander og håper det etter hvert vil kunne være et nyttig supplement i klinikken for kontinuerlig og sensitiv overvåkning av hjernens blodstrøm.

Hans Torp og Siri Ann Nyrnes har begge vært med på å utvikle NeoDoppler og er blant medeierne av CIMON medical som kommersialiserer teknologien

\section{Conflict of interest}

NTNU and St. Olavs hospital, Trondheim University Hospital may benefit financially from a commercialization of the ultrasound equipment through future possible intellectual properties; this may include financial benefits to authors of this article. H.T. and S.A.N. are co-inventors of NeoDoppler and have part-time positions in CIMON Medical, the company that is responsible for commer- cialization of NeoDoppler. H.T. and S.A.N. are among the shareholders in CIMON Medical. S.S.Ø. and A.H.J. declare no conflict of interest.

\section{References}

[1] Knut Matre, "Norway - Technology," in EFSUMB History of Ultrasound, Christoph F. Dietrich, Ed. 2019.

[2] Vik SD, Torp H, Follestad T et al. NeoDoppler: New ultrasound technology for continuous cerebral circulation monitoring in neonates. Pediatr Res 2020; 87: doi:10.1038/s41390019-0535-0

[3] Jarmund AH, Ødegård SS, Torp $\mathrm{H}$ et al. Effects of tilt on cerebral hemodynamics measured by NeoDoppler in healthy neonates. Pediatr Res 2021. doi:10.1038/s41390-020-01354-w

[4] Genolini C, Alacoque X, Sentenac M et al. kml and $\mathrm{kml3d:} R$ packages to cluster longitudinal data. Journal of Statistical Software 2015; 65: 1-34

[5] Anthony MY, Evans DH, Levene MI. Neonatal cerebral blood flow velocity responses to changes in posture. Archives of Disease in Childhood 1993; 69: 304-308. doi:10.1136/ adc.69.3_Spec_No.304

[6] Ipsiroglu OS, Eichler F, Stoeckler-Ipsiroglu S. Cerebral doppler sonography of the neonate: A résumé after 20 years and future aspects. Clinics in Perinatology 1999; 26: 905-946. doi:10.1016/S0095-5108(18)30027-7 